\title{
Broader driver of disrespectful maternity care: power dynamics
}

\begin{abstract}
Understanding the dynamics under which women experiences birth and disrespectful care is important. It recognizes the relegation women experiences within a subjugated relationship between women and health care practitioners arising from power disparities. When power dynamics are acknowledged and everyone's expertise respected, women have positive and healthy childbirth with respect to human's fundamental right. This is the kind of care women want and need.
\end{abstract}

Keywords: power, dynamics, childbirth, disrespectful care, maternity
Volume 12 Issue 3 - 202I

\author{
Faith C Diorgu,' Awoala N George ${ }^{2}$ \\ 'Nurse/Midwife lecturer, PhD, RM, Department of Nursing \\ Science, University of Port Harcourt, Nigeria \\ ${ }^{2}$ Nurse/Midwife lecturer, M.Ed RM, RN, Department of Nursing \\ Science, University of Port Harcourt, Nigeria
}

\begin{abstract}
Correspondence: Faith C Diorgu, Nurse/Midwife lecturer, $\mathrm{PhD}, \mathrm{RM}$, Department of Nursing Science, University of Port Harcourt, Nigeria, Tel +2348033401555,
\end{abstract}

Email faith.diorgu@uniport.edu.ng

Received: April 27, 2021 | Published: May 12, 2021

\section{Background}

Many studies show that women in labour value discreet midwifery practice,,$^{1,2}$ particularly when care providers are open to listening to and caring about women during childbirth. Undoubtedly, majority of women have negative perceptions regarding the treatment they receive from healthcare providers during childbirth. ${ }^{3-5}$ Many women complain and report disrespectful care and mistreatment from their care providers. ${ }^{6-8}$ Many other women articulate lack of opportunities to express their views about the treatment and services received during childbirth. ${ }^{910}$ Health workers are being perceived as unapproachable and women being unaware of their rights as service users. In-addition, lack of accountability and apparent sanctioning of poor practices, attitude and behaviours within health facilities left women feeling powerless. Several recent studies ${ }^{11-13}$ clearly indicate that many women globally experience disrespectful care in health facilities when giving birth.

Browser and Hill ${ }^{14}$ describe seven categories of disrespectful care during childbirth: physical abuse, denial of autonomy, non-consented clinical care, non-confidential care, non-dignified care, discrimination, abandonment and detention in health facilities. Freedom and Kruk ${ }^{15}$ built on the Browser and Hill's categories to propose a different definition of disrespectful care during childbirth by articulating criteria for determining when an interaction or condition should be considered disrespectful care. They considered disrespectful care to be interactions or facility conditions that is generally accepted by the local consensus to be humiliating or undignified or intended to be humiliating or undignified..$^{15}$ Physical and verbal abuse by the healthcare providers that is deliberate or unintentional towards women as well as other health system constraints are considered as contributing factors to the behavior of individual. ${ }^{16}$ For example, staff shortages, poor infrastructure or lack of work material can create stressful working environment which may predispose health care providers to behave poorly to women. These factors can all impact on a woman's health, her childbirth experiences, and her rights to respectful, dignified, and humane care during childbirth. It is important to note that disrespectful conduct by health care providers may not always be intentional, and may coexist with other compassionate and more respectful care practices..$^{17}$ However, women's experiences of disrespectful care must be considered, regardless of intent. Health system factors may provide contextual explanations for negative experiences, but should not be considered as justification for the continued disrespect of women. However, disrespect to women during birth is not only related to the care issue, but also demonstrates human right violation. Every woman has the right to the highest attainable standard of health care. ${ }^{18,11,19}$ The disrespectful or uncompassionate care during childbirth can represent a show of power structure and power disparity leading to violation of women's fundamental human rights.

\section{Power dynamics}

Interpersonal power encompasses both "power to" which describes the ability of an individual to complete an action or behavior, and "power over," which refers to the ability to influence or control another person. Both manifestations of power are influenced by social and normative prescriptions related to gender, and a growing body of research has shown that low female autonomy is associated with poor experience of maternal health services. A challenge to research on power dynamics, however, is the lack of a clear operational definition of "power."

Nelson and Quick ${ }^{20}$ defined power as the ability to influence others. Social influences refer to changes in the beliefs, attitude or behaviour of a person (target of influence) which results from action of another person (an influencing agent). Therefore, social power holds the potential for such influence. The continual defining and redefining of power appears to have led to lack of focus. Goodrich ${ }^{21-23}$ argues that power can be conceptualised in two ways: "power-over' (domination) and "power-to" (personal empowerment). "Power-over" refers to domination and control of one or group over another. ${ }^{22}$ This concept is similar to the concept of "fate control" and "behaviour control" by Thibaut and Kelley's ${ }^{24}$ and French and Ravens' six bases of power. ${ }^{25}$ Ragins and Sundstrom, ${ }^{26}$ suggested a power-over analysis in which when the focus is on women and power, it provides the background for power- over to operate. Power-over has been argued in the broad context of patriarchy, looking at gender-based social, political, economic and sexual inequalities in power by feminist scholars. ${ }^{27-29}$ Seemingly, research involving power-over as noted by Ragins and Sundstroms ${ }^{26}$ primarily focuses on organisational, interpersonal 
and individual levels. The organisational power includes the work environment, and work procedures. Interpersonal power-over is an aspect of dyadic interaction in which one person has the power to influence another within a specific relationship, mostly when women and power are on focus. ${ }^{26}$

Conversely, power-to or personal empowerment has to do with the control one feels over one's own thoughts, feelings and behaviours. ${ }^{30}$ Empowerment is often discussed within the broader context of social influences and change, ${ }^{31}$ except in Worell and Remer. ${ }^{32}$ However, empowerment and feminism are the restoration implements arising from women's movement. ${ }^{21}$ For example, in consistent with feminist agenda for social change, Ozer and Bandura provided women with knowledge, skills, self- beliefs and efficacy to be in control. ${ }^{22}$ One of the most significant theories of power comes from the work of French and Raven ${ }^{25}$ who identified sources of social power. This framework was selected for use in this review based on the notion that there exist inequalities among women both as mothers and midwives as they construct their experiences regarding disrespectful maternity care during childbirth. Customs of maternity care are highly related to the social structure and power. It is well established that power dynamics and specifically gender play a massive role in healthcare outcomes.

\section{Power disparity}

Disparities often occur on the basis of who has more power to either negatively or positively influence. Gender norms in any given society can lead to differences between males and females in regards to social position. This means those women's needs are constructed based on social position. Thus, situating dominated women are not able to confront power structure and social power influence. Great deal of power people exert comes from the specific job or position they hold, this means one is able to influence others because of the formal power associated with their position. ${ }^{24}$ Expert power as considered by Nelson and Quick $^{20}$ is the ability to influence others' behaviour because of recognised knowledge, skills or abilities. Experts are perceived to have expertise, credibility, and relevance and be trustworthy. ${ }^{25}$ Obstetricians are acknowledged to have expertise, special skills or abilities, thus are credited with expert power. Knowledge is power and also has influence. ${ }^{24}$ When individuals perceive or believe that one person possess superior skills or abilities, power is granted to the person. ${ }^{27}$

A person with expert power has the ability to influence obedient and compliance. Obstetricians and midwives who have shown tangible evidence of their expertise will be listened to closely by the women. Most women follow their health care provider's advice and directives. Thus, the social power construction of mother's disrespectful care during childbirth directly relate to the wider construction of expert power structure and that women (mothers and midwives) have constructed their experiences within a male dominated construct. In this sense, midwives and obstetricians are afforded with maternity expertise and have the ability to control the women's intrapartum process, whilst the midwives also construct their own experiences of the maternity care they give within the male construct that operates within the medical profession in which the obstetricians make all the decisions about maternity care. This is reinforced by evergrowing dependency of both the midwives and expectant mothers on the perceived expertise of midwives and obstetricians. That is, the midwives use their legitimate power of formal position and social norms to subdue the women under their care, whilst the obstetricians do the same to both the midwives and the expectant mothers which may result in disrespectful and abusive care. This depicts misuse of power and professional authority.
In addition, the male phenomenon is apparent in Western dominated culture and it is more closely tied to being in control. Professional dominance can be viewed from the lens of social theory of power by French and Raven ${ }^{25}$ as power being conceptualized as more to foster power dynamism and hierarchy amongst health professional in maternity. Noting cultural values, social norms and acceptance of social structure as the bases of legitimate power in healthcare system. Midwives as females are expected to be obedient to the obstetricians as they hold superior position as males in the healthcare system. The obstetricians use legitimate power as leaders in the healthcare team to influence and control midwives in the care of parturient women. This is because, legitimate power is underpinned by social norms. Thus midwives are often time subjugated and disempowered, the submissiveness supported the control of both midwives and mothers as a result of social power disparity. Thus, the professionals concede the dominant role and the women takes on a passive role in contexts ruled by the prevailing hospital norms and culture. This clearly demonstrates the inequality and a subservient relationship existing between the two maternity professional groups. This kind of suppressions is directly related to the wider construction of expert power structure and that women have built their experiences within an organizational dominated construct.

However, in contemporary feminism, the social power construction of mothers' experiences of disrespectful care support the notion to confront the power structures prevailing in the hospital birthing settings. It is believed that power is effective only when the target of powerful actions agrees to the relevant power dynamics. Both mothers and midwives can resist the power of social authority through the process of sharing clinical findings, information and communication. Nonetheless, using information can create a power base that serve to exert control and power over. Appropriate use of information power can decentralize power base, which in turn may promote self-reliance and prevent overdependence. Knowledge is power and also have influence. ${ }^{26}$ Therefore, provision of information to a person can result in changes in thinking and in their acting in a different way, ${ }^{25}$ especially if the information is accepted to be true. In order to establish information power, an agent of influence would likely provide baseline information to a target of influence to lay the groundwork in order to be effective. ${ }^{25}$ If midwives and obstetricians give adequate information to gravid women concerning birthing process and the expected outcomes, then the power of choice and decision making is given away by the care providers who originally possesses the information power. The mothers would then use the information power because knowledge can influence decision making, authority, and control to achieve a positive childbirth experience. However, timely and relevant information delivered on demand can be the most influential way to acquire this power. Therefore, it is of interest to know what bases of power or which power strategies are most likely to be effective, but it is clear that there is no simple answer Therefore, it is of interest to position women to be able to confront the power structures that serve to dominate women (mothers and midwives). The legitimate power of dependence based on the social norms of healthcare providers, social responsibility and obligation to support women should be loosened. ${ }^{33-36}$

\section{Conclusion}

Maternity care providers use legitimate and professional powers to relegate women to dependent and disempowered state. The dependent and disempowered situation has been described by other scholars. ${ }^{12,28,17}$ Several recent studies clearly indicate that many women globally have experienced similar dehumanized care and in many 
setting worldwide. Women childbirth experiences lack supportive care and denial of autonomy. A complex range of systemic failures in health facilities has contributed to the occurrence of controlled and disrespectful care, including poor supervisory structures, insufficient staff, flawed policies, rigid institutional culture and most importantly damaging power dynamics and power disparities that systematically disempower women. Greater attention needs to be paid to the issue of "Power" and Hierarchy, with consequent structural changes in order to achieve health services reform of respectful maternity care. Giving information can be the most transitory type of power. If one gives information away, then power is giving away to those who feel powerless. To promote respectful care of women, prior and in-service training, improvement of the working environment conditions, together with the empowerment of pregnant women and strengthening of health policies will be crucial in the best obstetric care. Regardless, efforts to provide care that meets the psycho-sociocultural needs of women are based on the ability and willingness of health professionals to provide it. The broader and interdisciplinary perspectives of disrespectful attitudes and behaviors of health personnel are crucial to improving the obstetric care environment for women to be successful.

\section{Acknowledgments}

None.

\section{Funding}

None.

\section{Conflicts of interest}

The authors report no declarations of interest.

\section{References}

1. Sheferaw ED, Bazant E, Gibson H, et al. Respectful maternity care in Ethiopian public health facilities. Reprod Health. 2017;14(1):60.

2. Lambert J, Etsane E, Bergh A-M, et al. I thought they were going to handle me like a queen but they didn't': A qualitative study exploring the quality of care provided to women at the time of birth. Midwifery. 2018;62:256-263.

3. Kassa ZY, Husen S. Disrespectful and abusive behavior during childbirth and maternity care in Ethiopia: A systematic review and meta-analysis. BMC Research Notes. 2019.

4. Banks KP, Karim AM, Ratcliffe HL, et al. Jeopardizing quality at the frontline of healthcare: prevalence and risk factors for disrespect and abuse during facility-based childbirth in Ethiopia. Health Policy Plan. 2017;33(3):317-327.

5. Gebremichael MW, Worku A, Medhanyie AA, et al. Mothers' experience of disrespect and abuse during maternity care in northern Ethiopia. Global Healt Action. 2018;11(sup3):1465215.

6. World Health Organization. The prevention and elimination of disrespect and abuse during facility-based childbirth. Geneva; 2014.

7. Bowser D, Hill K. Exploring evidence for disrespect and abuse in facility based childbirth. Boston: USAID-TRAction Project. Harvard School of Public Health; 2010.

8. Honikman S, Fawcus S, Meintjes I. Abuse in South African maternity settings is a disgrace: Potential solutions to the problem. SAMJ. 2015;105(4):284-286.

9. Mselle LT, Kohi TW, Mvangi A, et al. Waiting for attention and care: birthing accounts of women in rural Tanzania who developed obstetric fistula as an outcome of labour. BMC Pregnancy and Birth. 2011;11(1):1.
10. Okafor II, Ugwu EO, Obi SN. Disrespect and abuse during facility-based childbirth in a low-income country. Int J Gynaecol Obstet. 2015;128 (2): 110 .

11. Chadwick RJ, Foster D. Technologies of gender and childbirth choices: Home birth, elective caesarean and white femininities in South Africa. Feminism and Psychology. 2013;23(3):317-338.

12. Chadwick RJ, Cooper D, Harries J. Narratives of distress about birth in South African public maternity settings: A qualitative study. Midwifery. 2014;30(7):862-868.

13. Diorgu FC, Steen MP. Nigerian mothers' perceived disrespectful care during labour and birth arising from lack of choices for birthing position and episiotomy. J Gynec Obstet. 2017;1;015.

14. Bohren MA, Vogel JP, Hunter EC, et al. The mistreatment of women during childbirth in health facilities globally: a mixed-methods systematic review. PLoS Med. 2015;12(6):e1001847.

15. World Health Organization. Raising the voices of pregnant women in Poland. 2015.

16. World Health Organization. WHO recommendations: intrapartum care for a positive childbirth experience. Geneva: World Health Organization; 2018.

17. White Ribbon Alliance. Respectful maternity care: The universal rights of childbearing women. 2011.

18. Nelson DL, Quick JC. Understanding Organizational Behaviour. 4th edn. Mason, OH: South-Western/Cengage Learning; 2012.

19. Goodrich TJ. Women and power: Perspectives for family therapy. New York: Norton; 1991.

20. Goodrich TJ. Women, power, and family therapy: What's wrong with this picture? Journal of Feminist Family Therapy. 1991;3:5-37.

21. Kitzinger C. Feminism, psychology, and the paradox of power. Feminism and Psychology. 1991;1:111-129.

22. Thibaut JW, Kelley HH. The social psychology of groups. New York: Wiley; 1959.

23. French JP, Raven BH. A power/interaction model of interpersonal influence: French and Raven thirty years later. Journal of Social Behaviour \& Personality. 1992;7(2):217-244.

24. Ragins BR, Sundstrom E. Gender and power in organizations: A longitudinal perspective. Psychological Bulletin. 1989;105:51-88.

25. Millett K. Sexual politics. New York: Ballantine; 1970.

26. Connell RW. Gender and power. Palo Alto, CA: Stanford University Press; 1987.

27. Sanday PR. Female power and male dominance: On the origins of sexual inequality. New York: Cambridge University Press; 1985.

28. Bandura A. Human agency in social cognitive theory. American Psychologist. 1989;44:1175-1184.

29. Riger S. Vehicles for empowerment: The case of feminist movement organizations. Prevention in Human Services. 1984;3:99-117.

30. Worell J, Remer P. Feminist perspectioes in therapy: An empowerment model for women. Chichester, England: Wiley; 1992.

31. Ozer EM, Bandura A. Mechanisms governing empowerment effects: A self efficacy analysis. J Pers Soc Psychol. 1990;58:472-486.

32. Greenberg D, Landry EM. Negotiating a flexible work arrangement: how women navigate the influence of power and organizational context. Journal of Organisational Behaviour. 2011;32(8):1163-1188.

33. Petress K. Power: definition, typology, description, examples, and implications. 2003. 
34. Lunenburg FC. Power and leadership an influence process. International Journal of Management, Business, and Administration. 2012;15(1):1-9.

35. Forsyth DR. Group dynamics. 5th edn. Belmont. CA: Cengage; 2010.
36. Hatamleh R, Shaban IA, Homer C. Evaluating the experience of Jordanian women with maternity care services. Health Care for Women International. 201334(6):499-512. 